\title{
Foreword: Human rights and tobacco control - now more than ever
}

Smoking represents one of the largest public health crises of our times. The figures on tobacco use are nothing short of alarming. According to the World Health Organization (WHO), tobacco kills over 8 million people each year, while over 8 million people die of diseases related to tobacco use and around 1.2 million people die of diseases related to exposure to second-hand smoke (SHS). It is worrisome that over the years, these numbers have increased rather than declined.

The same WHO figures show that roughly 80 per cent of the 1.1 billion smokers worldwide live in low- and middle-income countries. These countries struggle greatly to counter strong tobacco industry lobbies and their marketing and sales strategies. The tobacco epidemic pushes families lacking household income into poverty. Children are involved in tobacco farming instead of attending school, and may grow up without their parents or other loved ones. And, most importantly, the disability caused and lives lost are preventable.

The WHO Framework Convention on Tobacco Control enshrines minimum standards on tobacco control and provides guideposts for countries to shape their domestic tobacco control policies. However, the death, disability and impoverishment caused by the tobacco epidemic also raises many concerns from a human rights perspective.

Although the tobacco industry has previously claimed human rights to property and freedom of expression to conduct its business, the tide is now turning. Increasingly, and I argue correctly, the emphasis is placed on the vulnerability of individuals when it comes to smoking and exposure to SHS. Scholars, practitioners and policy makers increasingly emphasize that in the context of tobacco, individual human rights, such as the rights to health, life and development, are key.

The question remains as to how these rights come into play precisely in the tobacco context. This is a matter that has thus far remained somewhat under-researched. This book systematically outlines the foundations, international legal architecture and domestic implementation of human rights approaches to tobacco control. 
I encourage policy makers, representatives of NGOs or international organizations and academics alike to consult this important work when integrating human rights in their tobacco control plans, strategies and frameworks.

Dainius Puras UN Special Rapporteur on the Right to Health 